\title{
Special issue on energy economics: demand, prices, and welfare. Editor's introduction
}

\author{
Isabel Soares ${ }^{1}$ - Óscar Afonso ${ }^{1}$
}

Received: 11 July 2016 / Accepted: 13 July 2016 / Published online: 20 July 2016

(C) ISEG 2016

The International Conference on Energy \& Environment: bringing together Economics and Engineering was held at the Faculty of Economics of the University of Porto, on May 9-10, 2013. This event which attracted 130 participants from 10 countries, aimed to bring together leading academic scientists, researchers and scholars from the energy and environment science community to interchange knowledge, to discuss and to disseminate new ideas towards a low-carbon, sustainable future.

In this special issue of the Portuguese Economic Journal (PEJ) on Energy Economics, we have selected three papers which deal with three critical problems in the literature: demand, prices, and welfare. Indeed, these topics are at the core of the energy transition(s) towards a decarbonized, sustainable economy as energy systems are crucial for economic growth and the quality of life. Moreover, they must be environmental friendly, reliable and affordable.

In the first paper, José M. Belbute and Alfredo M. Pereira evaluate the general issue of persistence in energy demand in Portugal. The analysis is approached in general terms using annual energy consumption data and a non-parametric procedure. In particular, they analyze the fractional integration in aggregate final energy demand in Portugal, with and without adjustments for seasonality, using an autoregressive fractionally integrated moving average model (ARFIMA), which is a generalization of the ARIMA model. The procedure allows for an identification of the type of memory that describes the diverse types of energy demand going beyond the usual stationary/nonstationary dichotomy. Results suggest the presence of long memory in the components of energy demand and stationary series. Thus, transitory shocks have long lasting effects and permanent effects require permanent policies.

Carlos Pinho and Mara Madaleno use MSVAR - the two-regime multivariate Markov switching vector autoregressive model - to contribute to the literature on the relationship between oil price movements and stock prices, by testing for nonlinear

Óscar Afonso

oafonso@fep.up.pt

1 Faculdade de Economia, Universidade do Porto, Porto, Portugal 
links and by using a sectoral focused view. The model allows the authors to capture the state shifts in the relationship between regional stock markets and sectors. Sudden changes are characterized by probabilistic statements called transition probabilities, postulating which regime occurs at each point in time. In particular, results suggest that oil price risk is meaningfully priced, asymmetric responses of sector stock returns to oil price changes, transmission impacts depend on the sector, and companies inside the utilities sector were more able to hedge against oil price increases between 2007 and 2012. Moreover, historical crisis do not seem to have affected the relationship between oil and sector stock returns. Finally, investors gain more through portfolio diversification benefits built across sectors.

Finally, António Brandão et al. provide an in-depth analysis of how the equilibrium market structure in the natural gas downstream market may be affected by the access conditions to the transmission grid. They also shed some light on the optimal regulatory policy regarding third party access to the transmission grid, address a market with ownership unbundling and then they study equilibrium outcomes arising in markets with lighter regulatory frameworks. It should be emphasized that welfare-maximizing tariffs often require free access to the transmission grid. Moreover, considering that the regulator's action is constrained by the break-even of the regulated firm, final prices in the downstream market are always higher with ownership unbundling than with legal unbundling.

We would like to thank the contributors to this special issue of PEJ for their work and cooperation. The three papers included in this issue have been extensively revised after the initial submission. We are grateful to the anonymous referees of the papers for their helpful and constructive comments. 